\title{
The Effect of Enforcement Fairness on Environmental Performance
}

\author{
Dietrich Earnhart (Corresponding author) \\ Department of Economics, University of Kansas, Lawrence, KS, USA \\ Tel: 785-864-2866Ｅ-mail: Earnhart@ku.edu
}

Robert L. Glicksman

The George Washington University Law School

George Washington University, Washington, DC, USA

Donna Ramirez Harrington

Department of Economics, University of Vermont, Burlington, VT, USA

Received: December 22, 2019 Accepted: March 3, 2020 Published: X, 2020

doi:10.5296/emsd.v9i2.16708 URL: https://doi.org/10.5296/emsd.v9i2.16708

\begin{abstract}
Many empirical studies explore the effects of regulatory enforcement on environmental behavior and performance. Within this literature, a few empirical studies explore environmental regulators' approach to enforcement, such as the contrast between a coercive strategy and a cooperative strategy. However, very little empirical research explores the role of fairness, which we interpret broadly to include multiple dimensions, e.g., similar treatment of similarly situated regulated entities. This study empirically analyzes the effect of enforcement fairness on the extent of compliance with wastewater discharge limits imposed on U.S. chemical manufacturing facilities. For this analysis, we use a subjective measure of the degree of "fair treatment" of the regulated facilities by the environmental regulator, as perceived by facilities and reported in response to an original survey. The empirical results robustly reveal that a less fair enforcement approach leads to better environmental performance, i.e., greater compliance.
\end{abstract}

Keywords: Environmental performance, Compliance, Enforcement, Wastewater 


\section{Introduction}

For years, scholars and environmental policymakers have conducted a spirited debate about the best means of ensuring compliance with environmental laws through enforcement. This debate over enforcement is greatly warranted since compliance assurance represents one of the most contentious issues in the post-2000 EPA policy agenda (EPA, 2000; Glicksman and Earnhart, 2007). The debate considers many aspects of enforcement. In particular, the debate addresses environmental regulators' approach to enforcement. For example, the debate assesses the comparative merits of a coercive enforcement strategy and a cooperative enforcement strategy (Markell, 2000; Markell, 2005; Mintz, 1995; Stoughton et al., 2001; Andreen, 2007; Burby and Patterson, 1993; Kagan et al., 2003). This debate on the enforcement approach chosen and implemented by the environmental regulator is all the more policy relevant since environmental protection agencies enjoy great discretion over their enforcement decisions (Craig, 2010; Johnson, 1999; Lazarus and Tai, 1999; Stafford, 2011).

Fairness represents a highly important element of the regulator's enforcement approach. This element involves multiple nuances. As the most prominent, enforcement fairness reflects the extent to which the environmental enforcement agency treats similarly situated regulated entities similarly (Rechtschaffen, 1998; Kagan, 1994; Costle, 1982). The other prominent nuance of fairness relates to the rigor of enforcement. A regulated entity might regard enforcement as "unfair" because the enforcement is harshly and punitively applied. For our empirical analysis, we broadly interpret fairness to include these two prominent nuances, along with other possible nuances.

A surprisingly limited literature explores the issue of enforcement fairness within the realm of compliance with environmental protection laws (Rechtschaffen, 1998; Kagan, 1994; Costle, 1982; White, 1996). This literature hypothesizes that unfair enforcement leads to less environmental compliance, worse environmental performance, or weaker environmental behavior (Rechtschaffen, 1998; Kagan, 1994; Costle, 1982).

Of course, this literature lies within a broader literature that examines the fairness of environmental protection laws (Lazarus, 1997; Lazarus, 1993; Tarlock, 1992; Hsu, 2004; Schroeder, 1993; Zinn, 2002), as opposed to their enforcement. For example, environmental regulation is commonly perceived by regulated entities as "unfair" partially because it does not provide flexible means of compliance (Zinn, 2002). ${ }^{1}$ As one of the primary objectives, this broader literature explores whether regulated entities comply better with environmental protection laws perceived as "fair". 2

More important, very little empirical research explores the role of fairness in environmental

\footnotetext{
${ }^{1}$ Other prominent reasons for this perception of unfairness include the following: (1) regulation requires a control level that regulated entities consider to lie beyond their technological or economic capabilities, (2) regulated entities do not believe that stringent regulation is needed to achieve a higher level of environmental quality, and (3) regulated entities believe that their industry faces a tighter regulation than faced by other industries.

${ }^{2}$ Our study does not explore the overall fairness of environmental protection laws. Instead, our study explores the fairness by which these laws are enforced.
} 
enforcement as a means for inducing environmental compliance. As a matter of fact, we are aware of only two empirical studies: White (1996) and Earnhart et al. (2020).

Local community pressure also influences environmental compliance. This pressure comes in various forms such as letters sent to facility managers, letters sent to local newspapers, petitions, and complaints to city hall. A rich literature explores the effect of local community pressure on environmental compliance or management (e.g., Earnhart, 2004c; Earnhart, 2009; Earnhart and Segerson, 2012; Pargal and Wheeler, 1996).

Neither of these aforementioned literatures explores the possible synergies between enforcement fairness and local community pressure. In particular, no study explores the influence of local community pressure on the effect of enforcement fairness.

Our study contributes to these two literatures by examining the effect of enforcement fairness on the environmental performance generated by chemical manufacturing facilities that are regulated under the National Pollutant Discharge Elimination System Permit (NPDES) program, which represents the EPA's implementation of the Clean Water Act (CWA) as it relates to point sources of wastewater discharges. As important, our study explores the influence of local community pressure on the effect of enforcement fairness. In the process, we assess whether enforcement fairness and local community pressure are complements or substitutes. Enforcement fairness reflects a key component of regulatory pressure. Both regulatory pressure and community pressure send signals to regulated facilities for them to control their discharges. If these two forms of pressure generate signals that resonate, thus producing synergistic effects on facilities' compliance decisions, then these two external pressure forms represent complements. In contrast, if the two forms of external pressure generate signals that drown out each other, thus weakening both forms' effectiveness at inducing better compliance, then regulatory pressure and local community pressure represent substitutes.

For our empirical exploration, we examine the extent of compliance with wastewater discharge limits as measured by the ratio of actual discharges to permitted discharges, i.e., discharge ratio (Earnhart, 2004a,b; Earnhart, 2009; Earnhart and Segerson, 2012; Shimshack and Ward, 2005). By examining the extent of compliance, our study is able to examine both improvement toward compliance and improvement beyond compliance, as well as degradation away from compliance. This ability is very important for two reasons. Fairness may generate so much goodwill that regulated facilities are induced to over-comply. ${ }^{3}$ Local community pressure may also induce over-compliance. Conversely, unfair enforcement may generate so much ill will that regulated facilities choose to increase their extent of non-compliance, i.e., under-compliance. ${ }^{4}$ Exploration of both aspects represents a strong

\footnotetext{
${ }^{3}$ We acknowledge that, in a context of stochastic discharges, regulated facilities are not deterministically choosing among three outcomes - over-compliance, compliance, and non-compliance. Instead, regulated facilities are choosing the probability of being compliant. Given this perspective, the presence of over-compliance may reflect the choice to generate a high probability of compliance rather than the choice to go "beyond compliance".

${ }^{4}$ Of course, fairness may also lead to under-compliance.
} 
contribution to the very thin empirical literature..$^{5}$

For our empirical examination, we conducted an original survey of all chemical manufacturing facilities that were regulated under the federal Clean Water Act (CWA) between 1999 and 2001. One survey question seeks to capture enforcement fairness by instructing the surveyed facilities to describe the treatment that they had received from their wastewater regulators in terms of "fairness", as reflected in the enforcement of the Clean Water Act provisions. ${ }^{6,7}$ A separate survey question seeks to capture local community pressure by instructing each surveyed facility to describe its perceived need to respond to local community pressure.

Our empirical analysis exploits these survey questions in order to estimate the link from enforcement fairness to the extent of compliance and the influence of local community pressure on this link. Our base empirical results indicate that a less fair enforcement approach appears to induce better environmental performance, i.e., greater compliance with wastewater discharge limits. These results are robust to the choice of the regressor set used to establish the functional relationship involving environmental performance. These empirical results imply that environmental regulators seeking to induce better compliance should enforce less fairly. Put differently, our results imply that environmental regulators should not be overly fair, otherwise, the regulators may lose their leverage with regulated facilities. Perhaps "excessive" fairness dulls the deterrence generated by enforcement. However, based on our extended empirical results, the influence of enforcement fairness depends on the presence of local community pressure. Specifically, the effectiveness of less fair enforcement grows as local community pressure builds, implying that lesser fairness and local community pressure are complements. ${ }^{8}$ As important, our extended results reveal that lesser fairness proves more effective than greater fairness only when local community pressure is sufficiently meaningful. When local community pressure is weak, greater fairness proves more effective than lesser fairness.

In general, our empirical results contradict conventional wisdom. Consequently, future theoretical research should more closely examine the issue of enforcement fairness. As important, our empirical analysis broadly interprets fairness to include multiple nuances without discerning the effects of the individual nuances. Thus, our analysis identifies the

\footnotetext{
${ }^{5}$ Clearly the discharge ratio represents the outcome of many environmental management actions. Fairness directly affects these actions. Our analysis explores the culmination of these actions: discharges.

6 The survey refers to "regulators" as the personnel of the EPA regional offices and state environmental agencies who interact with the regulated facilities. These personnel do not create environmental regulations but instead implement them. As noted below, these personnel possess very little discretion when imposing limits on the amount of pollution discharged under the Clean Water Act, yet these personnel enjoy great discretion over enforcement. Given this contrast, we focus on the fairness of enforcement, which we interpret broadly enough to include both enforcement actions and monitoring inspections.

7 Our same original survey asks the facilities regulated under the Clean Water Act to describe the general enforcement approach employed by their wastewater regulators based on the simple dichotomy between cooperation and coercion. Nearly all of the surveyed facilities identified the general enforcement approach as cooperative. Thus, we see no need to explore the issue of cooperation versus coercion. As important, we should view our exploration of fairness fully within the context of a generally cooperative enforcement strategy.

${ }^{8}$ As described below, by construction, these same results imply that greater fairness and local community pressure are substitutes.
} 
overall effect of these multiple nuances. Since our empirical results identify a role for enforcement fairness broadly interpreted, future empirical research should seek to identify the separate effects of the individual nuances.

Since a regulator must choose its extent of enforcement fairness, this regressor might be endogenously determined. However, we use an instrumental variables estimator to demonstrate that our primary regressor appears exogenously determined. Therefore, our exploration of the causal link from enforcement fairness to environmental performance is appropriate. ${ }^{9}$

Our empirical research may contribute more generally given the broad regulatory interest in enforcement approach, including the dimension of fairness. Beyond the realm of environmental protection, scholarly and policymaking communities are interested in the broad topic of enforcement approach in the realms of finance, tax compliance, occupational safety, food and drug safety, and consumer product safety (Ayers and Braithwaite, 1992).

The rest of this paper is organized as follows. Section 2 summarizes the limited literature on the role of fairness in environmental enforcement. Section 3 describes regulatory efforts to control water pollutant discharges. Section 4 constructs the analytical framework by describing the functional relationship between environmental performance and enforcement fairness, plus local community pressure, to be estimated. Section 5 describes the data. Section 6 explains the statistical analysis, while Section 7 presents the estimation results. Section 8 briefly discusses the policy and research implications.

\section{Literature Review}

This section briefly reviews the limited literature on the role of fairness in environmental enforcement approaches as well as the literature on local community pressure. Some studies theoretically explore the role of enforcement fairness. Rechtschaffen (1998) theoretically examines the consistent treatment of similarly situated entities. This study posits that consistency of enforcement polices and practices induces in regulated entities the conviction that they are operating on a level playing field and "is essential to ensuring the credibility of an enforcement program and widespread voluntary compliance" (Rechtschaffen, 1998, pg. 1222-1223). Similarly, Costle (1982) posits that, other things being equal, the regulation that is perceived as most reasonable and fair is most likely to elicit compliance. As an alternative approach, Kagan (1994) theoretically examines the lack of regular and consistent enforcement of any regulatory regime, including an environmental protection regime. Kagan (1994) hypothesizes that the lack of regular and consistent enforcement erodes its deterrent effect, resulting in unpredictability, unequal treatment, and recalcitrance on the part of regulated entities who do not trust regulators to treat them in a manner they consider to be fair (Kagan, 1994). Each of these studies demonstrates that more fair enforcement should

\footnotetext{
${ }^{9}$ We acknowledge that we could explore the simultaneous determination of discharge ratio and enforcement fairness using simultaneous equations estimation. However, since we are not interested in the effect of the discharge ratio on enforcement fairness, we do not need to estimate enforcement fairness as a function of the discharge ratio. Our estimation of the discharge ratio is the sufficient component of any simultaneous equations estimation.
} 
induce greater compliance and less fair enforcement should induce weaker compliance.

To the best of our knowledge, only two studies empirically explore the role of fairness in environmental enforcement. White (1996) empirically examines the enforcement of regulations imposed on the operation of underground fuel tanks, which are designed to avoid leaking. This study reveals that enforcement was unclear and unpredictable, breeding resistance by tank owners to regulatory compliance efforts. Earnhart et al. (2020) empirically explore the influence of enforcement fairness on the effects of particular regulatory interventions, e.g., inspections, on environmental compliance.

While few studies explore environmental enforcement fairness, three broader literatures explore related dimensions. First, one broader literature explores the enforcement approach employed by an environmental regulator. In particular, a robust literature in the fields of law, political science, and economics explores the contrast between a coercive enforcement strategy and a cooperative enforcement strategy. Most studies explore this contrast theoretically (Kagan et al., 2003; Rechtschaffen and Markell, 2003; Scholz, 1984; Rechtschaffen, 1998). Other studies explore this contrast empirically (Helland, 1998; Harrison, 1995; Burby, 1995; Burby and Patterson, 1993; Andreen, 2007; Short and Toffel, 2008; Short and Toffel, 2010; Earnhart and Glicksman, 2015). ${ }^{10}$

Second, another broader literature explores the fairness of environmental protection laws themselves (Lazarus, 1997; Lazarus, 1993; Tarlock, 1992; Hsu, 2004; Zinn, 2002; Wiener, 1999), as opposed to their enforcement. As one example, Zinn (2002) explores the regulated entities' common perception of environmental regulation as "unfair" because it does not provide flexible means of compliance.

Third, our examination of enforcement fairness fits into a broader literature that explores environmental compliance and management and the role of regulatory pressure (e.g., Earnhart, 2004a, b; Earnhart, 2009; Earnhart and Segerson, 2012; Laplante and Rilstone, 1996; Shimshack and Ward, 2005; Magat and Viscusi, 1990).

Most relevant for our analysis, various studies in this broader literature explore the effect of local community pressure on environmental compliance or management decisions (e.g., Earnhart, 2004c; Earnhart, 2009; Earnhart and Segerson, 2012; Pargal and Wheeler, 1996). Similar to our study, some studies use a direct measure of local community pressure to explore its effect on environmental performance and/or behavior. Henriques and Sadorsky (1996) explore the effect of self-reported community pressure on Canadian firms' decisions to adopt an environmental plan. Dasgupta et al. (2000) uses World Bank survey data to explore the effect of self-reported community pressure (presence versus absence) on Mexican firms' decisions to adopt certain environmental management practices. Gangadharan (2006) uses the same World Bank survey data to examine the influence of local community pressure on the probability of a firm complying with environmental regulations; the results indicate that community pressure significantly raises this probability but the impact is minimal. Da Motta (2006) utilizes a survey of large Brazilian facilities to analyze corporate environmental

\footnotetext{
10 Additional studies explore the issue of cooperation versus coercion, such as studies conducted by Christine Park, Vibele Nielsen, and Peter May.
} 
performance; this study concludes that local community pressure, along with non-governmental organization (NGO) pressure, are the two main factors affecting facilities' environmental performance. ${ }^{11}$

None of these studies explores the role of fairness or assesses whether or how local community pressure influences the effect of regulatory pressure on regulated facilities' environmental or management decisions. Our exploration of regulatory enforcement pressure and local community pressure is most similar to the work by Pargal and Wheeler (1996) and Pargal et al. (1997) who explore the roles of formal and informal regulation by interpreting local community pressure as "informal regulation". Nevertheless, neither of these studies assesses whether formal regulation and "informal" regulation are complements or substitutes.

\section{Regulatory Context}

Our empirical analysis examines environmental performance relating to the U.S. Clean Water Act. We focus on wastewater discharges controlled by the Clean Water Act because, unlike other media, regulators systematically record wastewater discharge limits and actual discharges so that we are able to measure the extent of compliance rather than merely the status of compliance, which masks over-compliance and the degree of non-compliance. The Clean Water Act seeks to protect water quality mostly by controlling discharges from point sources of pollution. Based on the authority granted by this act, the U.S. Environmental Protection Agency (EPA) constructed the National Pollutant Discharge Elimination System (NPDES). Government efforts to control discharges begin with the adoption of regulatory standards that contain pollutant-specific discharge limits, which agencies impose on regulated facilities through the issuance of facility-specific permits. Although the EPA possesses the authority to issue permits, this authority has been delegated to states that meet federal criteria. The EPA and authorized state regulatory agencies issue permits through the efforts of permit writers.

When establishing the facility-specific discharge limits, permit writers consider two standards: (1) the Effluent Limitation Guideline standard, and (2) the state water quality-based standard. Effluent Limitation Guideline standards are designed to require a minimum level of wastewater treatment for a given industry (i.e., they establish a uniform upper bound on limits across the entire United States for a given industry). These standards are derived from available pollution control technologies. ${ }^{12}$ The state water quality-based standard is designed to ensure that the ambient water quality of the receiving water body meets state-based ambient quality standards. In other words, the discharge limit is set so that the facility's

\footnotetext{
11 Other studies use indirect measures of local community pressure to explore the effect of community pressure on environmental performance and/or behavior (e.g., Hamilton, 1993; Pargal and Wheeler, 1996; Maxwell et al., 2000; Becker, 2002; Earnhart, 2004c). Specifically, these studies examine polluters' responses to the potential for citizen action. These studies measure this potential using proxies for local community pressure. Generally these studies rely upon community characteristics to serve as the proxies.

12 If no industry-specific Effluent Limitation Guideline applies to the particular facility, the permit writer uses his/her Best Professional Judgment; in particular, the permit writer evaluates the effect of a permitted discharge limit on the environment. In the studied sample, the role for professional judgment is highly limited since nearly all of the facilities operate in sub-sectors with Effluent Limitation Guidelines. Thus, the scope for negotiation over discharge limit levels, including any reflection of compliance history, is severely restricted in the sample.
} 
discharges do not cause the water body's ambient concentration of the relevant pollutant to exceed the acceptable level, which is designed to assure that the receiving waterbody can sustain designated uses, e.g., fishable, swimmable waters. Thus, discharge limits identified by state water quality-based standards differ across facilities and time.

After a limit is determined under each standard, the more stringent limit must be written into the permit. ${ }^{13}$

To ensure compliance with the issued permit limits, the EPA and state agencies periodically inspect facilities and take enforcement actions as needed. While the EPA retains authority to monitor and sanction facilities, state agencies are primarily responsible for monitoring and enforcement. Inspections represent the backbone of environmental agencies' efforts to monitor compliance and collect evidence for enforcement (Wasserman, 1984); inspections also maintain a regulatory presence (EPA, 1990). In addition, agencies use a mixture of informal enforcement actions (e.g., warning letters) and formal enforcement actions, which include both penalties (i.e., fines) and formal enforcement actions that do not represent penalties, e.g., administrative orders.

Given the regulatory framework described above, it is worth highlighting the distinction between permit writers, who establish the stringency of discharge limits, and enforcement agencies, who implement enforcement strategies. In this study, we focus exclusively on enforcement strategies and whether they are perceived as more fair or less fair. As noted above, the permit writing process is largely dictated by EPA-issued regulations and state water quality standards. Put differently, permit writers often possess very little discretion when imposing limits. Consequently, we purposively choose not to explore the fairness by which permit writers impose discharge limits. Moreover, given the limited discretion granted to permit writers, we view discharge limit levels as exogenously determined and disregard the opportunity for permit writers to coordinate with enforcement personnel. ${ }^{14}$ In stark contrast to permit writers, environmental agency inspectors and enforcement personnel enjoy great discretion over their decisions. Given this contrast, our study of fairness focuses on enforcement, including monitoring inspections.

Point sources generally divide into two categories: municipal wastewater treatment facilities and industrial sources. Our study focuses on a single sector within the category of industrial sources: chemical manufacturing facilities. This focus on a single sector is consistent with

\footnotetext{
${ }^{13}$ Since the state water quality-based standards may trump the Effluent Limitation Guideline standards, effluent limits differ across facilities and time. Thus, our consideration of discharges relative to limits seems strongly meaningful.

14 These points notwithstanding, we acknowledge that, in the past few years or so, EPA policies have begun to grant more discretion to permit writers in certain settings and encouraged cooperation between permit writers and enforcement officials. First, Total Maximum Daily Loads (TMDLs), which have been implemented in a substantial number of watersheds, allow permit writers to allocate the TMDL across polluters operating in the same watershed. Second, the Next Generation Compliance initiative encourages permit writers to construct permits with more flexible monitoring requirements as a means for inducing better compliance on the part of regulated facilities; this mission of compliance assurance generally falls under the umbrella of enforcement. Neither of these policy developments was relevant during our sample period. In addition, the EPA has not developed its Next Generation Compliance initiative to any meaningful extent yet, and the TMDL program is a relatively recent focus of regulatory attention, so our conclusions remain relevant in general.
} 
other empirical studies of industrial pollution (e.g., Laplante and Rilstone, 1996; Shimshack and Ward, 2005; Earnhart, 2009).

The sector of chemical and allied products serves as an excellent vehicle for examining corporate environmental performance. First, the EPA has demonstrated a strong interest in this sector as evidenced by its study, jointly authored with the Chemical Manufacturing Association (CMA), on the root causes of noncompliance in this sector (EPA, 1999) and its study on the compliance history for this sector (EPA, 1997). Consistent with this interest, two sub-sectors in the industry, industrial organics and chemical preparations (SIC-codes 2869, 2899), were regarded by the EPA as priority sectors during a portion of the study period. Second, the CMA, now known as the American Chemistry Council (ACC), has demonstrated a strong interest in promoting pollution reduction and prevention with its Responsible Care initiative. Third, this sector is responsible for a significant portion of the nation's industrial output and a meaningful portion of all wastewater discharges by facilities subject to Clean Water Act regulation. ${ }^{15}$

Lastly, as noted above, discharge limits are pollutant-specific. Thus, our analysis must focus on certain pollutants in order to assess the extent of compliance. Our study focuses on the pollutant most common to the sampled facilities - total suspended solids (TSS). As important, this pollutant represents one of the five EPA conventional pollutants, which have at times been the focus of EPA enforcement efforts. As further support, many previous studies of wastewater discharges examine TSS (e.g., Earnhart, 2009; Laplante and Rilstone, 1996).

\section{Analytical Framework}

To assess the role of enforcement fairness, this section structures the statistical analysis that estimates a functional relationship between environmental performance and the extent of enforcement fairness. Given the empirical thrust of our study, we do not offer a conceptual framework. Instead, we rely upon previous theoretical studies (shown in Section 2) to generate the hypothesis that greater enforcement fairness leads to better environmental performance including greater compliance (Rechtschaffen, 1998; Costle, 1982; Kagan, 1994). Our empirical analysis tests this basic hypothesis.

\subsection{Effect of Enforcement Fairness}

In each relevant year of the sample, a facility chooses its level of environmental performance as reflected in the extent of compliance with the facility's wastewater discharge limit, which is represented by the ratio of actual discharges to permitted discharges, i.e., discharge ratio. The facility's chosen discharge ratio represents the dependent variable in our statistical analysis. The chosen discharge ratio depends on enforcement fairness, along with other explanatory variables, which collectively represent the regressors in our statistical analysis.

For our statistical analysis, we capture enforcement fairness using the perception of fair treatment of the facility by the regulator. This primary regressor takes a value of one when enforcement is more fair and a value of zero when enforcement is less fair.

\footnotetext{
15 The chemical industry is not necessarily representative of all industrial sectors. Indeed, its unique attributes contribute to our interest in studying it.
} 
To test the enforcement fairness hypothesis, we first estimate a functional relationship between environmental performance and a set of regressors. Then we assess the estimated effect of enforcement fairness on environmental performance, i.e., test whether the coefficient associated with the enforcement fairness regressor differs positively or negatively from zero.

\subsection{Effects of Other Factors on Environmental Performance}

In order to isolate the effect of enforcement fairness on environmental performance for proper testing, our statistical analysis controls for the influence of other explanatory factors (hereafter "control factors"), particularly government interventions - inspections and enforcement actions. Within a simple conceptual framework, these control factors relate to either the costs of compliance or the costs of non-compliance. We identify the control factors according to these two categories. As we identify these control variables, we also describe the a priori expectations regarding the relationship between each control factor and the dependent variable of discharge ratio.

The first set of control factors relates to the costs of compliance. First, compliance costs depend on abatement methods, which we measure as the presence or absence of an end-of-pipe treatment technology and self-audits. The presence of end-of-pipe treatment is expected to lower the chosen discharge ratio. Moreover, audits conducted by the facilities should improve the effectiveness of the existing abatement methods, which lowers the marginal costs of abatement. Given a lower marginal abatement cost, facilities should choose to abate more, implying that an increase in audits should decrease the chosen discharge ratio. Second, facility and firm characteristics influence compliance costs. The type of production process as proxied by broad sectoral classification - "organic chemicals" versus "inorganic chemicals" versus "other chemicals" - influences compliance costs but without a priori expectations regarding the effect of production process on the chosen discharge ratio. Compliance costs also depend on ownership structure, which we measure by contrasting publicly held structures from all other ownership structure. Facilities owned by publicly held firms are expected to discharge less (i.e., lower discharge ratio) because publicly held firms enjoy greater access to external financing. Compliance costs additionally depend on the firm-level ratio of environmental employees to total employees, which we interpret as a proxy for firm-level commitment to environmental protection or at least the quantity of resources available from corporate staff. Facilities owned by firms with more environmental employees are expected to discharge less (i.e., lower discharge ratio).

The second set of control factors relate to the costs of non-compliance. These factors primarily reflect regulatory pressure, which we divide into monitoring and enforcement. We measure regulatory monitoring based on the prevalence of inspections. Consistent with the standard deterrence model (Becker, 1968), we construct a factor that measures the ex ante likelihood or threat of an inspection, which arguably approximates the likelihood of a sanction. To construct an exogenous measure of this ex ante threat, we assess inspections conducted at other similar facilities, specifically other regulated chemical manufacturing facilities operating in the same relevant jurisdiction (i.e., state or EPA region) in the current calendar year (Earnhart, 2004b; Earnhart, 2009; Earnhart and Glicksman, 2011). Given the 
discrete nature of monitoring, we simply count the inspections conducted at other similar facilities, while dividing by the number of "other similar facilities" in the jurisdiction in the current year for comparability across space and time. Based on work by Earnhart (2004b), we derive two separate measures for state inspections and federal inspections. These measures serve collectively as a proxy of the perceived threat of inspections based on others' experiences (Sah, 1991). Obviously, a greater threat of monitoring is expected to lower the chosen discharge ratio.

We measure regulatory enforcement based on the strength of enforcement. Specifically, we construct three variables that collectively measure the ex ante strength of enforcement. To construct exogenous measures, we assess enforcement actions taken against other similar facilities. In the case of penalties, we measure the inflation-adjusted dollar value of penalties levied on other similar facilities, while dividing by the number of regulated facilities. In the case of non-penalty enforcement, we count the enforcement actions taken against other similar facilities, while dividing by the number of regulated facilities. We derive two separate measures for informal enforcement and formal non-penalty enforcement. These measures collectively serve as a proxy of the perceived strength of the enforcement threat based on others' experiences (Sah, 1991). Similar to monitoring, the threat of stronger enforcement is expected to lower the chosen discharge ratio. ${ }^{16,17}$

As other regulatory control factors, we incorporate individual EPA region indicators and individual calendar year indicators, which contain no obvious a priori expectations.

Our statistical analysis also controls for investor pressure. We allow ownership structure to control for both variation in compliance costs, as discussed above, and variation in investor pressure. Facilities owned by publicly held firms are expected to discharge less because publicly held firms face greater pressure from investors for good environmental performance.

\footnotetext{
${ }^{16}$ We purposely use regulatory measures based on inspections conducted at and enforcement actions taken against other similar facilities, while avoiding measures based on inspections and enforcement experienced by the specific facility, since the latter measures are not likely to be exogenously determined. As important, the constructed variables better reflect ex ante measures of monitoring and enforcement, which are consistent with the theoretical deterrence model, than would variables derived from the specific facility's own experiences with inspections and enforcement.

${ }_{17}$ To construct effective ex ante measures of monitoring and enforcement, our study uses current government interventions against other facilities, similar to previous studies (Earnhart, 2004b; Earnhart, 2009; Earnhart and Glicksman, 2011). Still, we acknowledge the empirical literature does not use a single approach. A different set of studies uses lagged government interventions against other facilities (e.g., Shimshack and Ward, 2005). Our use of current government interventions implies that facilities' expectations are forward looking, whereas the use of lagged government interventions implies that expectations are backward looking. The use of current government interventions or forward-looking expectations generates better ex ante measures because this approach accommodates policy or regime changes. For example, enforcement regimes, including budgetary allocations, can change dramatically when new administrations take over the executive branch, such as when new U.S. presidents and state governors take control over environmental agencies. The use of lagged government interventions or backward-looking expectations completely fails to anticipate these abrupt changes in the likelihood and severity of enforcement. Moreover, the use of forward-looking expectations is based on the assumption that facilities possess rational expectations about the calendar year's interventions. (Our use of calendar year measures is not problematic since we aggregate all factors to an annual basis.) Under rational expectations, regulated facilities process all available information to generate an unbiased prediction of future government interventions, which helps regulated facilities to maximize their profits (or reach some alternative objective).
} 
As the last control factor, we include the lagged discharge ratio. In practice, enforcement authorities consider a facility's compliance history - both current and lagged discharge ratios - when exploring sanctions for non-compliance, consistent with EPA guidelines. Thus, the higher the discharge ratio was in the past, the greater is the impact of an increased current discharge ratio on the threat of sanction. Given this connection, a higher lagged discharge ratio leads to a greater marginal cost of non-compliance, prompting the facility to lower its currently chosen discharge ratio; the converse also holds.

\subsection{Role of Local Community Pressure}

Finally, we explore the role of local community pressure. As noted in the introduction, this pressure comes in the form of letters sent to facility managers, letters sent to local newspapers, petitions, and complaints to city hall. As more extreme but unlikely forms, local community members may boycott a facility or even blockade a facility's gates. We measure local pressure by the facility's perceived need to respond to local community pressure, as expressed in response to the aforementioned survey question. We distinguish between a "strong need to respond" and a less than "strong need to respond". Facilities facing a greater need to respond to local community pressure are expected to discharge less (i.e., lower discharge ratio). Theoretically greater local community pressure increases the cost of non-compliance (Pargal and and Wheeler, 1996; Dasgupta et al., 2000; Earnhart, 2004c; Gangadharan, 2006), prompting facilities to re-balance the trade-off between the costs of compliance and non-compliance by lowering discharges (i.e., improving their extent of compliance). In this regard, local community pressure plays a role similar to any external pressure factor, e.g., regulatory pressure, investor pressure.

Conceptually, regulatory pressure and local community pressure may serve as complements or substitutes for inducing better environmental compliance. If these two forms of pressure generate signals that resonate, thus producing synergistic effects on facilities' compliance decisions, then these two external pressure forms represent complements. For example, a facility may not respond positively to enforcement pressure unless the facility feels pressure from local community members to protect the local environmental quality in the form of letters to the local newspaper or requests for face-to-face meetings with facility management. In this case, the marginal effect of regulatory enforcement pressure grows as local community pressure builds. In contrast, if the two forms of external pressure generate signals that drown out each other, thus weakening both forms' effectiveness at inducing better compliance, then regulatory pressure and local community pressure represent substitutes. For example, a facility may ignore regulatory pressure if the facility is already facing pressure from local community members in the form of protests and boycotts. In this case, the marginal effect of regulatory enforcement pressure declines as local community pressure grows. Most interesting, whether the two external pressure forms are complements or substitutes depends on the extent of enforcement fairness since fairness and unfairness clearly send different types of regulatory signals that may amplify or dampen the signal of local community pressure. Consequently, we use the extent of enforcement fairness to capture regulatory pressure as it relates to local community pressure. 
We assess whether regulatory enforcement pressure (i.e., fairness) and local community pressure are complements or substitutes by generating an interaction between these two explanatory factors and incorporating this interaction term into our regressor set for estimating the extent of compliance.

\subsection{Explanatory Variables used by Previous Studies}

Previous empirical studies of environmental compliance and management employ explanatory factors similar to ours: treatment technology (Earnhart, 2004a,b,c), audits (Evans et al., 2011; Khanna and Widyawati, 2011), sectoral classification (Khanna et al., 2007; Ervin et al., 2013; Henriques and Sadorsky, 1996; Earnhart, 2009), ownership structure (Arimura et al., 2008; Dasgupta et al., 2000; Khanna et al., 2007; Earnhart, 2009), government monitoring (Earnhart, 2004a,b,c; Earnhart, 2009; Earnhart and Segerson, 2012; Anton et al., 2004; Evans et al., 2011), enforcement actions (Khanna et al., 2009; Harrington et al., 2008; Earnhart, 2004a,b,c), EPA regional indicators (Earnhart, 2009; Earnhart and Segerson, 2012), local community pressure (Earnhart, 2004c; Earnhart, 2009; Earnhart and Segerson, 2012; Pargal and Wheeler, 1996), investor pressure (Ervin et al., 2013; Khanna et al., 2007), and lagged discharge ratio (Magat and Viscusi, 1990; Harrington, 2012; Earnhart, 2004a,b,c).

\section{Data}

In order to explore the influence of enforcement fairness on Clean Water Act-regulated facilities' wastewater discharge ratios and the role of local community pressure, we explore data drawn from a survey of regulated facilities and an EPA database.

\subsection{Survey of Regulated Entities}

This first sub-section describes the set of facilities sampled by the survey and the information extracted by the survey. Our survey was administered to a sample of U.S. chemical manufacturing facilities whose wastewater discharges were regulated by discharge limits imposed within permits issued as part of the National Pollutant Discharge Elimination System (NPDES) in 2001. The population of CWA-regulated facilities in the chemical manufacturing industry as of September, 2001 was extracted from the EPA's Permit Compliance System (PCS) database, which records information on facilities permitted within the NPDES system. In order to screen for currently regulated facilities, we applied the following criteria to facilities: (1) possessed an NPDES permit; (2) faced restrictions on their wastewater discharges, (3) were operating as of 2002, and (4) discharged pollutants into surface water bodies. ${ }^{18}$ Application of these criteria identified 1,003 facilities to contact. Of those facilities contacted between April of 2002 and March of 2003, 267 facilities completed the survey, implying a $27 \%$ response rate. This rate is comparable to previous large-scale surveys of industrial sectors (e.g., Arimura et al., 2008; Arimura et al., 2011; Nakamura et al., 2001) and lies above the average response rate of $21 \%$ as identified by a review of 183 studies using business surveys that were published in academic journals (Paxson, 1992). [The

\footnotetext{
${ }^{18}$ We focus on facilities discharging into surface water bodies because facilities discharging into publicly owned treatment works (POTW) systems, i.e., industrial users, face a distinctively different regulatory regime.
} 
appendix addresses the possible concern of sample selection bias. $]^{19}$

When administering the survey, we first contacted those individuals responsible for signing their respective facilities' wastewater discharge monitoring reports, which facilities are required to submit to the EPA on a regular basis, generally monthly. This selection of survey participants allows our survey to exploit the insight of those individuals most knowledgeable about their facilities' wastewater operations. The survey gathered various data elements. Mostly the survey gathered annual data for the years 1999, 2000, and 2001. The survey gathered data on environmental management (e.g., audits), characteristics of the facilities, and characteristics of the firms that own these facilities (e.g., ownership structure) ${ }^{20}$ Most important, the survey gathered data on the extent of enforcement fairness employed by a wastewater regulator against a specific facility by asking each respondent to characterize the prevalence of its regulator's fair treatment: always unfair, sometimes fair and sometimes unfair, or always fair. The specific wording of the survey question is as follows: "From the following options, how would you characterize the manner in which the water regulator you typically work with treats your facility and its employees: (a) always unfair; (b) sometimes unfair, sometimes fair; (c) always fair?"21

Another survey question asked respondents to assess their perceived need to respond to local community pressure. The specific wording of the survey question is as follows: "Which of the following best describes the attitudes that managers of your facility have towards the facility's need to respond to local community concerns about the environment: (a) little concern about the need to respond, (b) some concern, (c) quite a bit of concern, or (d) a great deal of concern?"

We claim that our use of a self-reported, subjective measure of local community pressure dominates the standard use of local community demographics, e.g., per capita income, which merely serve as proxies of local community pressure. This said, we acknowledge that our direct measure of local community pressure may be shaped by a facility management's desire, rather than its need, to respond to local community pressure. In this regard, our measure may not accurately capture the pressure generated by local communities. Despite this potential drawback, we claim that even a partially flawed direct measure dominates local community demographic measures.

\footnotetext{
19 Twelve published studies utilize the data provided by this survey; citations are withheld to retain the anonymity of the authors.

${ }^{20}$ To validate the self-reported data on firm ownership structure, our study draws upon publicly available data. The EPA Toxic Release Inventory (TRI) database provides annual information on a facility's parent company. The Business and Company Resource Center database and Compustat / Research Insight database provide annual data on a parent company's ownership structure.

${ }^{21}$ Our survey also poses questions to explore the relationship between a regulated facility and its regulator, i.e., the regulatory agency official generally working with the facility. Responses to these questions may provide insight on a facility's perception of enforcement fairness. One question asks whether anyone in the facility has asked the supervisor of the facility's regulator to help the facility with a difference of opinion between the facility and the regulator. Of the surveyed facilities, $19.2 \%$ claimed that they had. Another question asks whether anyone in the facility has asked a local, state, or federal elected official to help the facility with a difference of opinion between the facility and the regulator. Of the surveyed facilities, $4.7 \%$ claimed that they had.
} 


\subsection{Publicly Available Data on Regulated Entities}

To complement the data gathered by our survey, we also collected information from the EPA Permit Compliance System (PCS) database. This database provides information on each facility's (1) location, (2) four-digit standard industrial classification [SIC] code, (3) monthly limit levels of permitted discharges, and (4) monthly levels of actual discharges. ${ }^{22}$ From these data, we calculate the monthly discharge ratio. We focus exclusively on the most prominent wastewater pollutant in the sample: total suspended solids (TSS). The PCS database also provides data on government interventions: inspections conducted by federal and state regulators, formal enforcement orders imposed by federal administrative and civil courts, and informal enforcement actions issued by federal enforcement agencies.

The NPDES system includes both "minor facilities" and "major facilities" as classified by the EPA; in general, minor facilities are smaller and major facilities are larger. ${ }^{23}$ The PCS database systematically records wastewater discharges and discharge limits only for major facilities. Not surprisingly, the PCS database contains no information on discharge limits and wastewater discharges for any of the 164 survey respondent minor facilities. Of the 103 survey respondent major facilities, the PCS database contains records that potentially provide data on discharge limits and wastewater discharges for 97 major facilities. For all of our analysis, we focus exclusively on these 97 facilities for which we possess both survey data and EPA data on limits and discharges. ${ }^{24}$

Our exclusive focus on major facilities clearly limits the generalizability of our results. Nevertheless, our analysis remains strongly policy relevant since the EPA focuses its regulatory efforts on major facilities (Earnhart, 2004a,b; Earnhart, 2009; Earnhart and Segerson, 2012). In addition, major facilities vary among themselves along several dimensions, including the regulatory pressure they face in terms of inspections and enforcement actions, their environmental management practices, and product mix, as reflected in the standard deviations shown in the summary statistics provided in Table 1. Thus, the empirical analysis is able to exploit variation even within a sample of only major facilities. Moreover, major facilities represented $21 \%$ of the chemical manufacturing facilities operating within the NPDES system in 2001. Given their size, we suspect that major facilities were responsible for the bulk of wastewater discharges from this sector during the sample period. $^{25}$ Lastly, all previous studies of U.S. wastewater discharges focus exclusively on major facilities (e.g., Earnhart, 2004a; Shimshack and Ward, 2005; Earnhart, 2009; Earnhart

\footnotetext{
${ }^{22}$ The analysis aggregates the four-digit SIC codes into three broader sectoral categories: organic chemicals, inorganic chemicals, and "other" chemicals. The broad category of organic chemicals includes the following four-digit SIC codes: 2821, 2823, 2824, 2843, 2865, 2869, 2891, and 2899. The broad category of inorganic chemicals includes the following four-digit SIC codes: 2812, 2813, 2816, 2819, 2873, and 2874.

${ }^{23}$ For the classification of each regulated facility, the EPA calculates a major rating with points assigned on the basis of toxic pollution potential, flow type, conventional pollutant load, public health impact, and water quality impact; the EPA classifies any discharger with a point total of 80 or more as a "major facility".

24 Our regression sample of 97 major facilities represents $31.2 \%$ of the major facilities contacted for our survey.

${ }^{25}$ The EPA does not systematically maintain data on discharges from minor facilities for any sector. The data coverage of the EPA Discharge Monitoring Report (DMR) Pollutant Loading Tool, which is designed to provide data on discharge loadings, confirms this point; see http://cfpub.epa.gov/dmr. Thus, we are not able to substantiate our assertion.
} 
and Segerson, 2012). ${ }^{26}$

To match the annual data provided by the survey for the years 1999 to 2001, we aggregate the monthly data on discharge ratios to an annual basis by identifying the year-specific median discharge ratio among the 12 monthly discharge ratios. (Use of the year-specific mean discharge ratio generates highly similar estimation results.)

Prior to this aggregation, we assess the reporting of discharges. Of the monthly observations relevant to TSS discharge limits, $99.5 \%$ also provide data on actual TSS discharges. This nearly universal reporting of wastewater discharges is quite reassuring and practically eliminates the need to consider strategic non-reporting of discharges.

In sum, the sample represents a panel of 97 facilities with annual data for the years 1999, 2000, and 2001. Thus, the unit of observation is an individual facility discharging in a given year. However, not all 97 facilities discharge TSS in all three years so the regression sample is smaller. Further, by first-differencing our variables, which is required by our chosen estimation procedure (as described in the next section), we effectively use only two years of data. In the end, the TSS regression sample includes 144 observations.

\subsection{Summary Statistics}

Table 1 statistically summarizes the dependent variables and the various independent variables. Information on the dependent variables is most interesting. Based on the average TSS discharge ratio of 0.232 , the average facility discharges TSS at levels $77 \%$ below its limits $[(1-0.232) \times 100=76.8 \%]$. Clearly, many facilities are choosing to overcomply.

Table 1. Descriptive Statistics of Variables: Means, Standard Deviations (in parentheses)

\begin{tabular}{|c|c|c|}
\hline Variable & Variable Description [Units] & $\begin{array}{l}\text { TSS } \\
\text { Sample }\end{array}$ \\
\hline \multicolumn{3}{|l|}{ Dependent Variable } \\
\hline \multirow[t]{2}{*}{ Discharge Ratio } & \multirow[t]{2}{*}{ Ratio of measured discharges to permitted discharges [ratio] } & 0.232 \\
\hline & & $(0.183)$ \\
\hline \multicolumn{3}{|l|}{ Primary Regressor } \\
\hline Enforcement Fairness & $\begin{array}{l}\text { Facility's perceived fairness of regulator's treatment: }=1 \text { if always } \\
\text { fair; }=0 \text { if sometimes fair / unfair [dummy indicator] }\end{array}$ & $\begin{array}{l}0.838 \\
(0.370)\end{array}$ \\
\hline \multicolumn{3}{|l|}{ Control Factors } \\
\hline \multirow{2}{*}{$\begin{array}{l}\text { Firm Environmental } \\
\text { Employees }\end{array}$} & \multirow{2}{*}{$\begin{array}{l}\text { Ratio of firm-level environmental employees to all firm-level } \\
\text { employees [ratio] }\end{array}$} & $(0.370)$ \\
\hline & & $(0.140)$ \\
\hline \multirow{2}{*}{$\begin{array}{l}\text { Organic } \\
\text { Sub-sector }\end{array}$} & \multirow{2}{*}{$\begin{array}{l}=1 \text { if facility in organic chemical sub-sector; }=0 \text { otherwise } \\
\text { (benchmark: "other chemical") [dummy indicator] }\end{array}$} & 0.625 \\
\hline & & $(0.486)$ \\
\hline
\end{tabular}

26 These points notwithstanding, we acknowledge that major and minor facilities might respond differently to the extent of enforcement fairness. Given our data limitations, we are not able to assess this possibility. Moreover, we acknowledge that major and minor facilities might face different variation in enforcement fairness. If true, the extent of enforcement fairness implemented depends on the NPDES major/minor classification. However, our analysis of the full sample of surveyed facilities reveals no statistical link from major/minor classification to enforcement fairness. (This conclusion is robust across a variety of econometric estimators, regressor sets, and sub-sample time periods.) Thus, this concern does not seem relevant in our sample. 


\begin{tabular}{|c|c|c|}
\hline \multirow{2}{*}{$\begin{array}{l}\text { Inorganic } \\
\text { Sub-sector }\end{array}$} & \multirow{2}{*}{$\begin{array}{l}=1 \text { if facility in inorganic chemical sub-sector; }=0 \text { otherwise } \\
\text { (benchmark: "other chemical") [dummy indicator] }\end{array}$} & 0.222 \\
\hline & & $(0.417)$ \\
\hline \multirow[t]{2}{*}{ Treatment Technology } & \multirow{2}{*}{$\begin{array}{l}\text { Treatment technology presence (vs absence): Average between TSS } \\
\text { and BOD technology [dummy indicator avg] }\end{array}$} & 0.920 \\
\hline & & $(0.202)$ \\
\hline Audits & Number of audits conducted per year [count per year] & $\begin{array}{l}2.764 \\
(8.936)\end{array}$ \\
\hline \multirow[t]{2}{*}{ Firm Ownership Structure } & \multirow[t]{2}{*}{$=1$ if firm is publicly held, $=0$ otherwise [dummy indicator $]$} & 0.917 \\
\hline & & $(0.277)$ \\
\hline \multirow{2}{*}{$\begin{array}{l}\text { Informal Enforcement } \\
\text { Threat }\end{array}$} & \multirow{2}{*}{$\begin{array}{l}\text { Ratio of informal enforcement actions against other similar facilities } \\
\text { and number of others [count per facility] }\end{array}$} & 0.110 \\
\hline & & $(0.156)$ \\
\hline \multirow{2}{*}{$\begin{array}{l}\text { Formal Non-Penalty } \\
\text { Enforcement Threat }\end{array}$} & \multirow{2}{*}{$\begin{array}{l}\text { Ratio of formal non-penalties against other similar facilities and } \\
\text { number of others [count per facility] }\end{array}$} & 0.043 \\
\hline & & $(0.057)$ \\
\hline \multirow{2}{*}{$\begin{array}{l}\text { Penalty } \\
\text { Threat }\end{array}$} & \multirow{2}{*}{$\begin{array}{l}\text { Ratio of penalties against other similar facilities and number of } \\
\text { others [ } \$ \text { per facility] }\end{array}$} & 1.235 \\
\hline & & $(5.944)$ \\
\hline \multirow[t]{2}{*}{ State Inspections Threat } & \multirow{2}{*}{$\begin{array}{l}\text { Ratio of state inspections at other similar facilities and number of } \\
\text { others [count per facility] }\end{array}$} & 1.419 \\
\hline & & $(1.319)$ \\
\hline Federal Inspections Threat & $\begin{array}{l}\text { Ratio of federal inspections at other similar facilities and number of } \\
\text { others [count per facility] }\end{array}$ & $\begin{array}{l}0.051 \\
(0.070)\end{array}$ \\
\hline \multirow[t]{2}{*}{ EPA Region 2} & \multirow{2}{*}{$\begin{array}{l}=1 \text { if facility in EPA Region } 2 ;=0 \text { otherwise (benchmark: Regions } \\
1,8,9,10 \text { ) [dummy indicator] }\end{array}$} & 0.083 \\
\hline & & $(0.277)$ \\
\hline \multirow[t]{2}{*}{ EPA Region 3} & \multirow{2}{*}{$\begin{array}{l}=1 \text { if facility in EPA Region } 3 ;=0 \text { otherwise } \\
\text { (benchmark: Regions } 1,8,9,10 \text { ) [dummy indicator] }\end{array}$} & 0.111 \\
\hline & & $(0.315)$ \\
\hline \multirow[t]{2}{*}{ EPA Region 4} & \multirow{2}{*}{$\begin{array}{l}=1 \text { if facility in EPA Region } 4 ;=0 \text { otherwise } \\
\text { (benchmark: Regions } 1,8,9,10 \text { ) [dummy indicator] }\end{array}$} & 0.347 \\
\hline & & $(0.478)$ \\
\hline \multirow[t]{2}{*}{ EPA Region 5} & \multirow{2}{*}{$\begin{array}{l}=1 \text { if facility in EPA Region } 5 ;=0 \text { otherwise (benchmark: Regions } \\
1,8,9,10) \text { [dummy indicator] }\end{array}$} & 0.083 \\
\hline & & $(0.277)$ \\
\hline \multirow[t]{2}{*}{ EPA Region 6} & \multirow{2}{*}{$\begin{array}{l}=1 \text { if facility in EPA Region } 6 ;=0 \text { otherwise } \\
\text { (benchmark: Regions } 1,8,9,10 \text { ) [dummy indicator] }\end{array}$} & 0.347 \\
\hline & & $(0.478)$ \\
\hline \multirow[t]{2}{*}{ EPA Region 7} & \multirow{2}{*}{$\begin{array}{l}=1 \text { if facility in EPA Region } 7 ;=0 \text { otherwise } \\
\text { (benchmark: Regions } 1,8,9,10 \text { ) [dummy indicator] }\end{array}$} & 0.014 \\
\hline & & -0.117 \\
\hline \multirow[t]{2}{*}{ Year 2001} & \multirow[t]{2}{*}{$=1$ if year is $2001 ;=0$ if year is 2000 [dummy indicator] } & 0.507 \\
\hline & & -0.502 \\
\hline \multirow{2}{*}{$\begin{array}{l}\text { Local Community } \\
\text { Pressure }\end{array}$} & \multirow{2}{*}{$\begin{array}{l}\text { Facility's perceived need to respond to local community concerns: = } \\
1 \text { if quite bit/great deal, }=0 \text { if little/some [dummy indicator] }\end{array}$} & 0.929 \\
\hline & & $(0.258)$ \\
\hline Number of Observations & & 144 \\
\hline
\end{tabular}

Table 1 also describes the extent of enforcement fairness within the sample of regulated facilities. As shown, $84 \%$ of the sampled facilities report that their regulatory treatment is "always fair", while $16 \%$ report that their regulatory treatment is "sometimes fair and sometimes unfair". No facility retained in the sample used for empirical analysis reports that its treatment is "always unfair". Thus, the distinction simplifies to the dichotomy between 
more fair treatment ("always fair treatment") and less fair treatment ("sometimes fair and sometimes unfair treatment”). We acknowledge that our enforcement fairness indicator does not vary much in our sample; yet we are still able to identify a statistically significant link from enforcement fairness to discharge ratio, despite the limited variation.

Table 1 also summarizes our measure of local community pressure. As shown, $93 \%$ of the sample facilities report that they perceive a strong need to respond to local community concerns, while $7 \%$ report that they perceive little to some need to respond. As with enforcement fairness, we acknowledge that our local community pressure indicator does not vary substantially in our sample; nevertheless, our analysis is still able to identify a statistically significant connection from local community pressure to the extent of compliance. $^{27}$

\section{Statistical Analysis}

This next section describes the statistical analysis used to explore the gathered data.

Most important, our statistical analysis addresses two key issues. First, it addresses the inclusion of the lagged dependent variable as a regressor in a panel data framework. In the presence of a lagged dependent variable, a fixed effects estimator generates inconsistent estimates because the differenced lagged dependent variable is correlated with the error term (Anderson and Hsiao, 1982). ${ }^{28}$ To address this complication, we employ the two-stage Anderson-Hsiao estimator (Anderson and Hsiao, 1982) as applied by Jaffe and Stavins (1995) and Harrington (2013). In the first stage, we first-difference all of the variables and estimate the first-differenced model in order to generate coefficients for the time-variant regressors using this equation:

$$
\Delta \mathrm{y}_{\mathrm{it}}=\alpha+\beta_{0} \Delta \mathrm{y}_{\mathrm{it}-1}+\beta_{1} \Delta \mathrm{x}_{\mathrm{it}}+\Delta \mu_{\mathrm{it}},
$$

where $y_{i t}$ and $y_{i t-1}$ represent the current and one-year-lagged discharge ratios, respectively, and $x_{i t}$ represents the explanatory variables. In the second stage, we recover coefficients for the time-invariant regressors. ${ }^{29}$ In this two-stage approach, the coefficients, including the

27 Other survey questions offer additional information on local community pressure. One question asks the following: "In terms of your facility's relations with the community, would you say that the community has a generally negative or generally positive assessment of your facility and its operations in relation to the environment? Please rank the community's assessment on a scale of 0 to 10 , with 0 meaning 'very negative' and 10 meaning 'very positive'." The average response equals 7.4. Another question inquires: "In the past 3 years, has your facility been the subject of any negative or positive media attention with respect to environmental issues. Of the responding facilities, $16.5 \%$ claimed negative media attention, $16.2 \%$ claimed positive media attention, and $5.0 \%$ claimed both negative and positive media attention. Other questions inquired about facility behavior: "In the past 3 years have representatives of your facility met with citizen-formed community groups, such as community action panels, over issues involving the environment". $60.6 \%$ of facilities claimed they had. A similar question asked: "In the past 3 years have representatives of your facility met with community leaders over issues involving the environment?". Of the responding facilities, $63.7 \%$ stated they had. Our analysis purposively avoids use of these factors as our measure of local community pressure since they surely represent endogenous regressors as they represent facility behavior or reflect past facility behavior.

28 We do not employ a random effects estimator since Hausman Test of Random Effects statistics do not indicate that the random effects estimates are consistent.

${ }^{29}$ We recover the coefficients of the time-invariant regressors in four steps. As the first step, for each facility, we multiply each coefficient derived in the first stage with the facility mean of that same variable. This multiplication generates facility-factor-specific products. As the second step, we sum these 
coefficient for the lagged dependent variable, are interpreted as the partial effects of changes in the explanatory variables on the discharge ratio, given a starting value for the discharge ratio. Thus, the coefficients' interpretations depend on the starting value of the dependent variable. Despite this dependence, the signs of the coefficients capture the directional changes associated with increases in the regressors.

Given the concern over the correlation between the lagged dependent variable and the error term, we assess whether the lagged dependent variable is endogenous using both a Wu-Hausman Exogeneity Test and a Durbin-Wu-Hausman Exogeneity Test. The test statistics reject the null hypothesis of exogeneity, given p-values of 0.002 and 0.002 , respectively. Hence, we instrument for the first-differenced one-year-lagged dependent variable using a two-year-lagged level of the dependent variable, as suggested by Anderson and Hsiao (1982) and employed by Jaffe and Stavins (1995) and Harrington (2013). ${ }^{30}$

As the second statistical issue, our analysis addresses the potential endogeneity of the enforcement fairness regressor. We address this potential concern by employing an instrumental variable (IV) estimator, for which we must identify at least one instrument for this potentially endogenous regressor. An effective instrument is both relevant, i.e., helps to explain the extent of enforcement fairness chosen by a regulator, and valid, i.e., does not influence the facility's choice of discharge ratio. To assess instrument validity, we must identify multiple instruments. Consistent with Anton et al. (2004), we lag key time-variant regulatory factors in order to generate instruments. In particular, we construct lagged measures of government intervention-related regressors, along with lagged measures of state-level audit-related immunity and privilege policies. [Several studies describe these policies (Short and Toffel, 2008, 2010; Toffel and Short, 2011; Khanna and Widyawati, 2011)]. By granting immunity from prosecution for violations self-disclosed by facilities generated from an internal audit program and/or granting privilege to evidence of violations generated from these audits, these policies arguably represent a more fair approach to environmental regulation. We argue that states adopting these audit policies enforce regulations more fairly. However, we claim that these audit policies should not influence the extent of compliance with wastewater limits. By federal statute, these audit policies cannot offer immunity or privilege to polluting facilities which are required to report their discharges as in the case of the Clean Water Act. While contemporaneous measures of these policies only immunity, only privilege, both immunity and privilege - should serve as valid instruments, we lag these factors in order to increase the validity of these instruments. Based on an assessment of the calculated statistics of standard tests, the instruments appear both

facility-factor-specific products to generate facility-specific sums. As the third step, we subtract the facility-specific sums from the mean of the dependent variable, which is measured in levels rather than differences. This subtraction generates the facility-specific "residuals". As the final step, we use ordinary least squares regression to estimate a functional relationship between the facility-specific residuals and the time-invariant factors in order to generate coefficients for the time-invariant factors. This approach yields consistent, but inefficient, estimates (Jaffe and Stavins, 1995; Harrington, 2013).

30 Since this technique is well-established and we choose to address the apparent endogeneity, we do not report the estimates generated within the intermediate steps. 
relevant and not invalid. ${ }^{31}$

Therefore, we test whether the potentially endogenous regressor of enforcement fairness is exogenous using both a Wu-Hausman Exogeneity Test and a Durbin-Wu-Hausman Exogeneity Test. These two test statistics fail to reject the null hypothesis of exogeneity given p-values of 0.266 and 0.221 , respectively. These statistics indicate that the enforcement fairness regressor does not appear endogenous. ${ }^{32}$ Performing IV estimation when a regressor is not endogenous (i.e., uncorrelated with the error process) involves an important cost: unnecessarily large standard errors (Wooldridge, 2003). ${ }^{33}$ Therefore, our statistical analysis proceeds by treating enforcement fairness as an exogenous regressor and addressing exclusively the problematic lagged dependent regressor.

We regard local community pressure as an exogenous regressor because the self-reported need to respond to local community pressure applies generally to any facility operating in the relevant community. The particular survey question does not inquire about pressure applied to the specific facility. (As noted in Footnote 27, other survey questions explore pressure applied to the specific facility or facilities' responses to local community pressure; we purposively avoid use of these factors since they are most likely endogenous.) ${ }^{34}$

In order to assess the robustness of our empirical results linking enforcement fairness to the chosen discharge ratio, we consider a variety of regressor sets, i.e., models. Model 1 includes only the enforcement fairness indicator and the lagged dependent variable, which represents the most parsimonious regressor set feasible when implementing the Anderson-Hsiao estimator. Model 2 adds the year indicator and EPA regional indicators. Model 3 includes all

31 To assess the relevance of our instruments, we primarily test under-identification in the first stage of estimation. Based on both the Angrist-Pischke $\chi^{2}$ Test statistics and the Anderson Canonical Correlation Lagrange Multiplier Test statistics, we reject the null hypothesis of under-identification given p-values of 0.068 and 0.088, respectively. As further evidence, we conduct a Partial F-test derived from the coefficients estimated for the instruments used in the first stage. Appendix Table A-1 displays the first-stage estimates. The Partial F-test statistic equals 2.53 , with a p-value of 0.050 . Thus, the five instruments are jointly significant at the $5 \%$ level. Two of the five instruments prove individually significant at the $5 \%$ level. Beyond the instruments, no other coefficients prove statistically significant. We interpret this lack of significance as evidence that enforcement fairness is idiosyncratic to a facility and its situation, i.e., not driven by other factors. From this perspective, the fairness measure seems to offers new information.

To assess the validity of our instruments, we primarily employ the Sargan-Hansen Test of Overidentifying Restrictions. The Sargan-Hansen Test statistic fails to reject the null hypothesis of valid orthogonality conditions given a p-value of 0.124. As further evidence, we employ weak instrument robust inference tests: the Anderson-Rubin Wald Test and the Stock-Wright Lagrange Multiplier Test. Regardless of the test, the statistics fail to reject the null hypothesis of valid orthogonality conditions with p-values of 0.201 and 0.124 , respectively. This assessment uses the relevant regressors in levels. If we take into account the endogeneity of the lagged dependent variable, the assessment uses the regressors in differences. This alternative assessment generates test statistics that comparably support our conclusions that the chosen instruments appear both relevant and not invalid.

${ }^{32}$ Using the relevant regressors in differences, which takes into account the endogeneity of the lagged dependent variable (as described in the preceding footnote), generates a test statistic that comparably supports our conclusion.

${ }^{33}$ This issue of unnecessarily large standard errors applies to all studies, not simply ours.

34 The audit-related regressor may be endogenous. However, exogeneity test statistics fail to reject the null hypothesis of exogeneity. (Details are available upon request.) Thus, we treat audits as exogenously determined with respect to the discharge ratio, consistent with Earnhart and Harrington (2014). 
of the regressors excepting the interaction between the enforcement fairness indicator and local community pressure. Model 4 includes all regressors.

For the sake of improving our estimation's fit of the data, we take logs of certain regressors: informal enforcement, formal non-penalty enforcement, penalty enforcement, state inspections, federal inspections, and the firm-level ratio of environmental employees to total employees.

As noted above, by using the Anderson-Hsiao estimator, which requires first-differences, we lose observations for the year of 1999 and must restrict our sample period to the years of 2000 and 2001; consequently, our regression sample includes 144 observations. $^{35}$

\section{Estimation Results}

This section reports and interprets the estimation results shown in Table 2. As noted in this table, the reported estimates reflect robust standard errors. ${ }^{36}$

Table 2. Anderson-Hsiao Estimation of Wastewater Discharge Ratios

\begin{tabular}{|c|c|c|c|c|c|c|c|c|}
\hline \multirow{2}{*}{$\begin{array}{l}\text { Variable } \\
\text { Enforcement Fairness }\end{array}$} & \multicolumn{2}{|c|}{ Model 1} & \multicolumn{2}{|l|}{ Model 2} & \multicolumn{2}{|c|}{ Model 3} & \multicolumn{2}{|c|}{ Model 4} \\
\hline & $\begin{array}{l}0.066 \\
(0.014)\end{array}$ & $* *$ & $\begin{array}{l}0.074 \\
(0.009)\end{array}$ & $* * *$ & $\begin{array}{l}0.090 \\
(0.003)\end{array}$ & $* * *$ & $\begin{array}{l}-0.484 \\
(0.000)\end{array}$ & $* * *$ \\
\hline Local Community Pressure & & & & & $\begin{array}{l}-0.152 \\
(0.008)\end{array}$ & $* * *$ & $\begin{array}{l}-0.515 \\
(0.000)\end{array}$ & $* * *$ \\
\hline $\begin{array}{l}\text { Enforcement Fairness } \times \\
\text { Local Community Pressure }\end{array}$ & & & & & & & $\begin{array}{l}0.615 \\
(0.000)\end{array}$ & $* * *$ \\
\hline Organic Chemical Sub-sector & & & & & $\begin{array}{l}0.072 \\
(0.090)\end{array}$ & $*$ & $\begin{array}{l}0.052 \\
(0.191)\end{array}$ & \\
\hline Inorganic Chemical Sub-sector & & & & & $\begin{array}{l}0.020 \\
(0.671)\end{array}$ & & $\begin{array}{l}0.045 \\
(0.306)\end{array}$ & \\
\hline Treatment Technology & & & & & $\begin{array}{l}0.115 \\
(0.097)\end{array}$ & $*$ & $\begin{array}{l}0.270 \\
(0.000)\end{array}$ & $* * *$ \\
\hline Audits & & & & & $\begin{array}{l}-0.003 \\
(0.015)\end{array}$ & $* *$ & $\begin{array}{l}-0.003 \\
(0.015)\end{array}$ & $* *$ \\
\hline Firm Ownership Structure & & & & & $\begin{array}{l}0.031 \\
(0.445)\end{array}$ & & $\begin{array}{l}-0.026 \\
(0.512)\end{array}$ & \\
\hline Firm Environmental Employees ${ }^{a}$ & & & & & $\begin{array}{l}-0.547 \\
(0.001)\end{array}$ & & $\begin{array}{l}-0.165 \\
(0.314)\end{array}$ & \\
\hline Informal Enforcement Threat $^{a}$ & & & & & $\begin{array}{l}0.052 \\
(0.842)\end{array}$ & & $\begin{array}{l}0.052 \\
(0.842)\end{array}$ & \\
\hline $\begin{array}{l}\text { Formal Non-Penalty } \\
\text { Enforcement Threat }^{\text {a }}\end{array}$ & & & & & $\begin{array}{l}-1.206 \\
(0.094)\end{array}$ & $*$ & $\begin{array}{l}-1.206 \\
(0.094)\end{array}$ & $*$ \\
\hline
\end{tabular}

${ }^{35}$ We do not adjust our standard errors in order to address any possible small sample concern.

${ }^{36}$ These standard errors are equivalent to those generated by clustering at the facility level. 


\begin{tabular}{|c|c|c|c|c|c|c|c|}
\hline Penalty Enforcement Threat ${ }^{a}$ & & & & $\begin{array}{l}0.006 \\
(0.478)\end{array}$ & & $\begin{array}{l}0.006 \\
(0.478)\end{array}$ & \\
\hline State Inspections Threat ${ }^{\text {a }}$ & & & & $\begin{array}{l}-0.147 \\
(0.140)\end{array}$ & & $\begin{array}{l}-0.147 \\
(0.140)\end{array}$ & \\
\hline Federal Inspections Threat ${ }^{a}$ & & & & $\begin{array}{l}0.018 \\
(0.953)\end{array}$ & & $\begin{array}{l}0.018 \\
(0.953)\end{array}$ & \\
\hline Lagged Discharge Ratio & $\begin{array}{l}0.086 \\
(0.644) \\
\end{array}$ & $\begin{array}{l}0.085 \\
(0.647) \\
\end{array}$ & & $\begin{array}{l}0.078 \\
(0.668) \\
\end{array}$ & & $\begin{array}{l}0.078 \\
(0.668) \\
\end{array}$ & \\
\hline Year 2001 & & $\begin{array}{l}-0.002 \\
(0.917)\end{array}$ & & $\begin{array}{l}0.007 \\
(0.809)\end{array}$ & & $\begin{array}{l}0.007 \\
(0.809)\end{array}$ & \\
\hline F-test: EPA Regions & & 2.44 & $* *$ & 3.13 & $* * *$ & 5.31 & $* * *$ \\
\hline Number of Observations & 144 & 144 & & 144 & & 144 & \\
\hline
\end{tabular}

Robust p-values shown in parentheses.

Asterisks indicate level of statistical significance: * 10\%; ** 5\%; *** $1 \%$.

EPA regions are included in the models, but individual coefficients are not reported.

Regression also includes a constant term.

${ }^{a}$ Regressors enter the estimation in log form.

\subsection{Base Empirics}

For our base set of empirical results, we focus on Models 1, 2, and 3, while ignoring the model that includes the interaction between enforcement fairness and local community pressure. In this way, we allow the estimates from Models 1, 2, and 3 to reveal the general effect of enforcement fairness. In sub-section 7.2, we explore the results from Model 4.

As shown in Table 2, estimates from Models 1, 2, and 3 reveal that enforcement fairness positively influences the discharge ratio. This positive coefficient implies that less fair treatment leads to better environmental performance, i.e., less fairness induces greater compliance with wastewater discharge limits. This result rejects the theoretical literature's hypothesis of greater fairness prompting better compliance. This conclusion is robust across the three relevant models. This conclusion is also robust to estimation of models that exclude either (1) all of the cost of compliance factors or (2) all of the cost of noncompliance factors; details are available upon request.

Perhaps consistent with the link from less fairness to better compliance, the estimation results reveal that the threatened strength of enforcement influences environmental performance. Most interesting, the estimates indicate that the threat of formal non-penalty enforcement negatively influences the discharge ratio. This negative coefficient indicates that an increased enforcement threat lowers the discharge ratio. Since the coefficient associated with the threat of informal enforcement is statistically insignificant, we conclude that enforcement must be formal in nature to prove effective. In contrast to formal non-penalty enforcement, the threat of penalty enforcement proves statistically insignificant, similar to informal enforcement. We discount this contrast and similarity based on the statistical insignificance of penalties since this form of enforcement is utilized so infrequently. Moreover, the estimates demonstrate that 
threatened enforcement, but not threatened monitoring in the form of inspections, proves effective. $^{37}$

As our second key form of external pressure, the significantly negative coefficient on the community pressure regressor indicates that a greater need to respond to local community pressure appears to lower discharge ratios.

Estimates also reveal the following links. First, the firm-level ratio of environmental employees to total employees negatively influences the discharge ratio. This link implies that a firm-level commitment to environmental management resources appears to improve environmental performance at the facility level. Second, estimates reveal that the type of production process, as proxied by sectoral classification, influences the discharge ratio. Facilities manufacturing organic chemicals generate a higher discharge ratio than facilities manufacturing "other chemicals". Third, the effect of audits on discharge ratios is negative and statistically significant. The negative coefficient indicates that an increase in the count of audits lowers the discharge ratio, indicating that audits effectively control wastewater pollution.

\subsection{Extended Empirics}

We next extend our empirics by exploring the interaction between enforcement fairness and local community pressure. As shown in Table 2, local community pressure significantly affects TSS discharge ratios. To explore the noted interaction, we assess the estimation results of Model 4 shown in Table 2. In particular, we assess the coefficients associated with enforcement fairness, local community pressure, and the interaction term. To start, the interaction term proves statistically significant, revealing that local community pressure influences the effect of enforcement fairness on the extent of compliance. Further interpretation of these coefficients is challenging because the two key underlying regressors are binary and a lower discharge ratio reflects better environmental compliance. To facilitate understanding, Table 3 reports the marginal effects of the enforcement fairness factor, conditional on the strength of local community pressure, while evaluating each level of enforcement fairness separately. As shown in Table 3, the marginal effect of greater fairness equals -0.484 when local community pressure is weak ("little/some") but equals +0.131 when local community pressure is strong ("quite bit / great deal"). Since a positive marginal effect indicates that greater fairness counter-productively raises discharge ratios, the effectiveness of greater fairness falls as local community pressure grows, implying that greater fairness and local community pressure are substitutes. Thus, these two external pressure signals appear to drown each other out. In contrast (and by construction), the marginal effect of less fairness equals +0.484 when local community pressure is weak ("little/some") but equals - 0.131 when local community pressure is strong ("quite bit / great deal"). Since a negative marginal effect indicates that less fairness effectively lowers discharge ratios, the effectiveness of less fairness grows as local community pressure builds, implying that less fairness and local community pressure are complements. Thus, these two

\footnotetext{
37 See Gray and Shimshack (2011) for a review of the results generated by previous empirical studies on the effectiveness of regulatory enforcement and monitoring.
} 
external pressure signals appear to resonate. Most interesting, these results reveal that less fairness dominates greater fairness only when local community pressure is sufficiently meaningful, which is true for $93 \%$ of the sample. When local community pressure is weak, greater fairness dominates less fairness. Based on the sample average strength of local community pressure, less fairness dominates greater fairness.

Table 3. Marginal Effect of Enforcement Fairness on Wastewater Discharge Ratios: Conditional on Local Community Pressure

\begin{tabular}{|l|l|l|l|}
\hline \multirow{2}{*}{$\begin{array}{l}\text { Extent of } \\
\text { Enforcement Fairness }\end{array}$} & $\begin{array}{l}\text { Strength of } \\
\text { Local Community Pressure }\end{array}$ & Marginal Effect \\
\cline { 3 - 4 } & & Magnitude & $\begin{array}{l}\mathrm{H}_{0} \text { : Effect }=0 \\
\text { F-Test Statistic p-value }\end{array}$ \\
\hline \multirow{3}{*}{$\begin{array}{l}\text { Greater } \\
\text { Fairness }\end{array}$} & Little / Some & -0.484 & 0.000 \\
\cline { 2 - 4 } & Quite Bit / Great Deal & 0.131 & 0.000 \\
\cline { 2 - 4 } & Average & 0.087 & 0.002 \\
\hline \multirow{2}{*}{$\begin{array}{l}\text { Fesser } \\
\text { Fairness }\end{array}$} & Little / Some & 0.484 & 0.000 \\
\cline { 2 - 4 } & Quite Bit / Great Deal & -0.131 & 0.000 \\
\cline { 2 - 4 } & Average & -0.087 & 0.002 \\
\hline
\end{tabular}

The extended empirical results also reveal that the marginal effect of local community pressure depends on enforcement fairness. Conditional on lesser fairness, the marginal impact is significantly negative (-0.515), implying that greater pressure improves the extent of compliance. However, conditional on greater fairness, the marginal impact is significantly positive $(+0.100$, implying that greater local pressure appears to undermine the extent of compliance.

\subsection{Economic Importance}

Lastly, we assess the economic importance of the influence of enforcement fairness. We first identify the mean discharge ratio, which is shown in Table 1. Based on the base empirics, we next identify the most representative enforcement fairness coefficient, which we believe stems from estimation of the most comprehensive regressor set: Model 3. (Use of the other models' coefficients generates a highly similar result.) Then we compare the coefficient to the mean discharge ratio. An increase in enforcement fairness prompts the discharge ratio to rise by 0.101 ; relative to a mean discharge ratio of 0.232 , this rise represents a $44 \%$ increase. This base empirical calculation appears to demonstrate that the influence of enforcement fairness is economically important.

We finally assess the economic importance based on the extended empirics, which consider the influence of local community pressure on the effect of enforcement fairness. When local community pressure is weak ("little/some"), an increase in fairness prompts the discharge ratio to fall by 0.484 ; relative to a mean discharge ratio of 0.232 , this drop represents a $209 \%$ decline. When local community pressure is strong ("quite bit / great deal"), an increase in fairness prompts the discharge ratio to rise by 0.131 ; relative to a mean discharge ratio of 0.232 , this rise represents a $56 \%$ increase. Again, these calculations appear to reveal that the 
influence of enforcement fairness is economically important.

\section{Conclusions, Policy Implications, and Future Research}

In this last section, we draw overall conclusions, discuss policy implications of our research results, and provide guidance on future research. Based on our base empirical results, we draw the following conclusion: less enforcement fairness appears to induce better environmental performance, i.e., greater compliance with discharge limits. These base results imply that environmental regulators should not be overly fair, otherwise, the regulators may lose their leverage with regulated facilities. Perhaps "excessive" fairness dulls the deterrence stemming from enforcement. Our results are robust to the choice of regressor set used to establish the functional relationship involving environmental performance. However, based on our extended empirical results, the influence of enforcement fairness depends on the presence of local community pressure. The effectiveness of less fairness grows as local community pressure rises, revealing that less fairness and local community pressure are complements. By construction, these same results reveal that greater fairness and local community pressure are substitutes. Moreover, our extended results demonstrate that less fairness dominates greater fairness only when local community pressure is sufficiently meaningful. When local community pressure is weak, greater fairness dominates less fairness.

These empirical results possess some troubling policy implications. Based on our results, in general, environmental enforcement agencies should act less fairly in order to induce better compliance with wastewater discharge limits. This same troubling policy implication applies when local community pressure is meaningful. Only if local community pressure is weak should agencies should act more fairly to induce better compliance. These troubling policy implications potentially conflict with federal regulations that seek to ensure that EPA implements not only a strong but also a "consistent enforcement and compliance monitoring program" (40 C.F.R. $\S 1.35$ ). In addition, these implications potentially conflict with constitutional doctrines, such as due process and equal protection, and judicial authority to reverse agency decisions found to be arbitrary and capricious. These doctrines constrain agencies' abilities to treat similarly situated regulated entities consistently.

We do not advocate that agencies act less fairly. Instead, we use our empirical results to identify two different types of policy implication. First, our results suggest that enforcement officials should identify grounds for differential treatment of regulated entities that do not run afoul of regulatory and constitutional constraints on unfairness and that will withstand judicial review, even if the regulated entities themselves regard such differential treatment as unfair. Empirical studies reveal that environmental protection agencies differentiate their enforcement strategies based on factors other than compliance history, such as local labor market conditions and facilities' financial situations (e.g., Deily and Gray, 1991; Gray and Deily, 1996). Economic theory explains this differentiation as a means for achieving cost-effectiveness, minimum environmental damages, or maximum political support (e.g., Dion et al., 1998; Earnhart, 2004b). Consider these examples. To achieve cost-effectiveness, agencies should enforce more strongly against facilities with lower marginal compliance 
costs. To minimize environmental damages, agencies should enforce more strongly against facilities located in more densely populated areas. To maximize political support, agencies should enforce less strongly against financially precarious facilities, who might lay off workers if they are fined. Seen through this lens, perhaps, without much greater effort, agencies can identify grounds for differential treatment that are legal yet regulated entities regard as unfair.

Second, agencies' adherence with the identified regulatory and constitutional protections may require agencies to miss the opportunity to induce better compliance from regulated facilities. Therefore, in certain contexts, these protections come at the expense of weaker compliance. Again, we do not advocate the removal of these protections. Instead, our results merely identify the "opportunity cost" of these protections.

These points notwithstanding, some of our empirical results generate policy insight that is not troubling. Greater fairness leads to better compliance as long as local community pressure is weak. Thus, agencies can act on some of our study's insight to improve compliance without violating regulatory and constitutional protections when and where ever local community pressure plays sufficiently limited role.

In closing, we acknowledge the limitations of our analysis and identify useful future research based on our results. First and foremost, our empirical analysis represents only an exploration of enforcement fairness interpreted broadly. This broad interpretation allows us to include multiple nuances of enforcement fairness, including the extent to which the enforcement agency treats similarly situated regulated entities similarly and the harshness of application. On the flip side, this broad interpretation constrains our analytical ability to discern the separate effects of the individual nuances. Instead, our empirical analysis is only able to capture the overall effect of these multiple nuances. Now that our empirical results establish a role for enforcement fairness broadly captured, we leave it to future empirical research to identify the individual nuance effects. Second, since our empirical results contradict conventional wisdom, future theoretical research should scrutinize more closely the role of enforcement fairness. Third, since our empirical results reveal a meaningful interaction between enforcement fairness and local community pressure, we encourage future research both empirical and theoretical - to explore more deeply this connection. Fourth, our conclusions need not generalize to other sectors regulated under the Clean Water Act or compliance with other environmental protection laws. Future research should expand the coverage of analysis. Specifically, we encourage future research to explore additional sectors beyond the chemical manufacturing sector, to explore a broader set of wastewater pollutants beyond TSS, and to explore pollution in other media, such as air pollution and toxic and hazardous waste generation.

\section{Acknowledgement}

The research described in this article was conducted as part of a larger project financed by the U.S. Environmental Protection Agency (EPA) pursuant to STAR Research Assistance Agreement No. R-82882801-0. This article has not been formally reviewed by EPA. The views expressed in this article are solely those of Robert Glicksman and Dietrich Earnhart. 


\section{Macrothink}

EPA does not endorse any products or commercial services mentioned in this manuscript. The authors thank Donald Haider-Markel and Tatsui Ebihara for their participation in the EPA STAR grant research project. The authors also thank Chris Drahozal, Joel Mintz, and Cliff Rechtschaffen for their very helpful insight. Robert Glicksman thanks Erica Dew for her valuable research assistance. Dietrich Earnhart thanks Dylan Rassier, J. Mark Leonard, and Trisha Shrum for their valuable research assistance.

\section{References}

Anderson, T., \& Hsiao, C. (1982). Formulation and estimation of dynamic models using panel data. Journal of Econometrics, 18(1), 47-82.

https://doi.org/10.1016/0304-4076(82)90095-1

Andreen, W. (2007). Motivating Enforcement: Institutional Culture and the Clean Water Act. Pace Environmental Law Review, 24, 67-98.

Anton, W. R., Deltas, G., \& Khanna, M. (2004). Incentives for environmental self-regulation and implications for environmental performance. Journal of Environmental Economics and Management, 48(1), 632-654. https://doi.org/10.1016/j.jeem.2003.06.003

Arimura, T. H., Darnall, N., \& Katayama, H. (2011). Is ISO 14001 a gateway to more Advanced voluntary action? The case of green supply chain management. Journal of Environmental Economics and Management, 61(2), 170-182.

https://doi.org/10.1016/j.jeem.2010.11.003

Arimura, T. H., Hibiki, A., \& Katayama, H. (2008). Is a voluntary approach an effective environmental policy instrument? Journal of Environmental Economics and Management, 55(3), 281-295. https://doi.org/10.1016/j.jeem.2007.09.002

Ayres, I., \& Braithwaite, J. (1992). Responsive regulation: Transcending the deregulation debate. New York, NY: Oxford Univ. Press.

Becker, G. S. (1968). Crime and punishment: An economic approach. Journal of Political Economy, 76(2), 169-217. https://doi.org/10.1086/259394

Becker, R. A. (2003). Pollution abatement expenditure by US manufacturing plants: do community characteristics matter?. Contributions in Economic Analysis \& Policy, 3(2). https://doi.org/10.2202/1538-0645.1231

Burby, R. J., \& Paterson, R. G. (1993). Improving compliance with state environmental regulations. Journal of Policy Analysis and Management, 12(4), 753.

https://doi.org/10.2307/3325349

Burby, R. J. (1995). Coercive versus cooperative pollution control: Comparative study of state programs to reduce erosion and sedimentation pollution in urban areas. Environmental Management, 19(3), 359-370. https://doi.org/10.1007/bf02471978

Costle, D. (1982). Environmental Regulation and Regulatory Reform. Washington Law Review, 57, 409-431. 


\section{Macrothink}

Environmental Management and Sustainable Development

ISSN 2164-7682 2020, Vol. 9, No. 2

Craig, R. K. (2010). The public health aspects of environmental enforcement. Pittsburgh Journal of Environmental and Public Health Law, 4. https://doi.org/10.5195/pjephl.2010.17

Da Motta, R. S. (2006). Analyzing the environmental performance of the Brazilian industrial sector. Ecological Economics, 57(2), 269-281. https://doi.org/10.1016/j.ecolecon.2005.04.008

Dasgupta, S., Hettige, H., \& Wheeler, D. (2000). What improves environmental compliance? Evidence from Mexican industry. Journal of Environmental Economics and Management, 39(1), 39-66. https://doi.org/10.1006/jeem.1999.1090

Deily, M. E., \& Gray, W. B. (1991). Enforcement of pollution regulations in a declining industry. Journal of Environmental Economics and Management, 21(3), 260-274.

https://doi.org/10.1016/0095-0696(91)90030-m

Dion, C., Lanoie, P., \& Laplante, B. (1998). Monitoring of Pollution Regulation: Do Local Conditions Matter? Journal of Regulatory Economics, 13(1), 5-18.

https://doi.org/10.1023/a:1007970031068

Earnhart, D. (2004). Panel data analysis of regulatory factors shaping environmental performance. Review of Economics and Statistics, 86(1), 391-401.

https://doi.org/10.1162/003465304323023895

Earnhart, D. (2004). Regulatory factors shaping environmental performance at publicly-owned treatment plants. Journal of Environmental Economics and Management, 48(1), 655-681. https://doi.org/10.1016/j.jeem.2003.10.004

Earnhart, D. (2004). The effects of community characteristics on polluter compliance levels. Land Economics, 80(3), 408. https://doi.org/10.2307/3654729

Earnhart, D. (2009). The influence of facility characteristics and permit conditions on the effectiveness of environmental regulatory deterrence. Journal of Regulatory Economics, 36(3), 247-273. https://doi.org/10.1007/s11149-009-9095-2

Earnhart, D., Glicksman, R., \& Harrington, D. (2020). The Effects of Enforcement on Corporate Environmental Performance: The Role of Fairness. Review of Law and Economics. https://doi.org/10.1515/rle-2019-0012

Earnhart, D., \& Segerson, K. (2012). The influence of financial status on the effectiveness of environmental enforcement. Journal of Public Economics, 96(9-10), 670-684.

https://doi.org/10.1016/j.jpubeco.2012.05.002

EPA (1990). A Primer on the Office of Water Enforcement and Permits and Its Programs. Office of Water, Environmental Protection Agency, Washington, DC, March 1990.

EPA (1997). Chemical Industry National Environmental Baseline Report 1990-1994, Office of Enforcement and Compliance Assurance, Environmental Protection Agency, EPA 305-R-96-002.

EPA (1999). EPA/CMA Root Cause Analysis Pilot Project: An Industry Survey, Environmental Protection Agency, EPA-305-R-99-001. 


\section{Macrothink}

Environmental Management and Sustainable Development

ISSN 2164-7682

2020, Vol. 9, No. 2

EPA (2000). U.S. EPA Strategic Plan 2000, Washington, DC: Environmental Protection Agency.

Ervin, D., Wu, J., Khanna, M., Jones, C., \& Wirkkala, T. (2012). Motivations and barriers to corporate environmental management. Business Strategy and the Environment, 22(6), 390-409. https://doi.org/10.1002/bse.1752

Evans, M. F., Liu, L., \& Stafford, S. L. (2011). Do environmental audits improve long-term compliance? Evidence from manufacturing facilities in Michigan. Journal of Regulatory Economics, 40(3), 279-302. https://doi.org/10.1007/s11149-011-9163-2

Glicksman, R., \& Earnhart, D. (2007). The Comparative Effectiveness of Government Interventions on Environmental Performance in the Chemical Industry. Stanford Environmental Law Journal, 26, 112-139.

Gray, W. B., \& Deily, M. E. (1996). Compliance and enforcement: Air pollution regulation in the u.s. steel industry. Journal of Environmental Economics and Management, 31(1), 96-111. https://doi.org/10.1006/jeem.1996.0034

Hamilton, J. T. (1993). Politics and social costs: estimating the impact of collective action on hazardous waste facilities. The RAND journal of economics, 101-125.

https://doi.org/10.2307/2555955

Harrington, D. R. (2012). Effectiveness of state pollution prevention programs and policies. Contemporary Economic Policy, 31(2), 255-278.

https://doi.org/10.1111/j.1465-7287.2011.00312.x

Harrington, D. R., Khanna, M., \& Deltas, G. (2008). Striving to be green: The adoption of total quality environmental management. Applied Economics, 40(23), 2995-3007.

https://doi.org/10.1080/00036840600994005

Harrison, K. (1995). Is cooperation the answer? Canadian environmental enforcement in Comparative context. Journal of Policy Analysis and Management, 14(2), 221. https://doi.org/10.2307/3325151

Helland, E. (1998). The enforcement of pollution control Laws: Inspections, violations, and self-reporting. Review of Economics and Statistics, 80(1), 141-153.

https://doi.org/10.1162/003465398557249

Henriques, I., \& Sadorsky, P. (1996). The determinants of an environmentally responsive firm: An empirical approach. Journal of Environmental Economics and Management, 30(3), 381-395. https://doi.org/10.1006/jeem.1996.0026

Hsu, S. (2003). Fairness versus efficiency in environmental law. SSRN Electronic Journal. https://doi.org/10.2139/ssrn.442420

Jaffe, A. B., \& Stavins, R. N. (1995). Dynamic incentives of environmental regulations: The effects of alternative policy instruments on technology diffusion. Journal of Environmental Economics and Management, 29(3). https://doi.org/10.1006/jeem.1995.1060 
John, D., \& Mintz, J. A. (1997). Enforcement at the EPA: High stakes and hard choices. Environmental History, 2(3), 384. https://doi.org/10.2307/3985369

Johnson, S. M. (1999). Economics v. Equity: Do Market-Based Environmental Reforms Exacrerbate Environmental Justice? Washington \& Lee Law Review, 56, 111-166.

Kagan, R. (1994). Regulatory Enforcement. In D. H. Rosenbloom \& R. D. Schwartz (Authors), Handbook of regulation and administrative law. New York: Dekker.

Kagan, R. A., Gunningham, N., \& Thornton, D. (2003). Explaining corporate environmental performance: How does regulation matter?. Law and Society Review, 37(1), 51-90. https://doi.org/10.1111/1540-5893.3701002

Khanna, M., \& Widyawati, D. (2011). Fostering regulatory compliance: The role of environmental self-auditing and audit policies. Review of Law \& Economics, 7(1). https://doi.org/10.2202/1555-5879.1483

Khanna, M., Koss, P., Jones, C., \& Ervin, D. (2007). Motivations for voluntary environmental management. Policy Studies Journal, 35(4), 751-772.

https://doi.org/10.1111/j.1541-0072.2007.00246.x

Khanna, M., Deltas, G., \& Harrington, D. R. (2009). Adoption of pollution prevention techniques: The role of management systems and regulatory pressures. Environmental and Resource Economics, 44(1), 85-106. https://doi.org/10.1007/s10640-009-9263-y

Laplante, B. \& Rilstone, P. (1996). Environmental inspections and emissions of the pulp and paper industry in Quebec. Journal of Environmental Economics and Management, 31(1), 19-36. Https://doi.org/10.1006/jeem.1996.0029

Lazarus, R. J. (1993). Pursuing 'Environmental Justice:' The Distrubutional Effects of Environmental Protection. Northwestern University Law Review, 87, 787-857.

Lazarus, R. J. (1997). Fairness in environmental law. Environmental Law, 27, 705-739.

Lazarus, R. J., \& Tai, S. (1999). Integrating Environmental Justice into EPA Permitting Authority. Ecology Law Quarterly, 26, 617-678. https://doi.org/10.2139/ssrn.209190

Magat, W. A., \& Viscusi, W. K. (1990). Effectiveness of the EPA'S regulatory enforcement: The case of industrial effluent standards. The Journal of Law and Economics, 33(2), 331-360. https://doi.org/10.1086/467208

Markell, D. (2005). 'Slack' in the Administrative State and its Implications for Governance: The Issue of Accountability. Oregon Law Review, 84, 1-22.

Markell. (2000). The role of deterrence-based enforcement in a 'reinvented' state / federal relationship: The divide between theory and reality. Harvard Environmental Law Review, 24, $1-5$.

Maxwell, J. W., Lyon, T. P., \& Hackett, S. C. (2000). Self-regulation and social welfare: The political economy of corporate environmentalism. The Journal of Law and Economics, 43(2), 
583-618. https://doi.org/10.1086/467466

Nakamura, M., Takahashi, T., \& Vertinsky, I. (2001). Why Japanese firms choose to certify: A study of managerial responses to environmental issues. Journal of Environmental Economics and Management, 42(1), 23-52. https://doi.org/10.1006/jeem.2000.1148

Pargal, S., \& Wheeler, D. (1996). Informal regulation of industrial pollution in developing Countries: Evidence from Indonesia. Journal of Political Economy, 104(6), 1314-1327.

https://doi.org/10.1086/262061

Pargal, S., Hettige, H., Singh, M., \& Wheeler, D. (1997). Formal and Informal Regulation of Industrial Pollution: Comparative Evidence from Indonesia and the United States. World Bank Economic Review, 11(3), 433-450. https://doi.org/10.1093/wber/11.3.433

Paxson, M. C. (1992). Response Rates for 183 Studies. Working Paper Washington State University, Washington State University.

Rechtschaffen, C. (1998). Deterrence vs. Cooperation and the Evolving Theory of Environmental Enforcement. Southern California Law Review, 71, 1181-1188.

Rechtschaffen, C., \& Markell, D. (2003). Reinventing Environmental Enforcement and the State/Federal Relationship, Washington, DC: Environmental Law Institute.

Sah, R. K. (1991). Social osmosis and patterns of crime. Journal of Political Economy, 99(6), 1272-1295. https://doi.org/10.1086/261800

Scholz, J. (1984). Cooperation, deterrence, and the ecology of regulatory enforcement. Law and Society Review, 18, 179-180. https://doi.org/10.2307/3053402

Schroeder, C. H. (1993). Cool Analysis Versue Moral Outrage in the Development of Federal Environmental Criminal Law. William \& Mary Law Review, 35, 251-269.

Shimshack, J. P., \& Ward, M. B. (2005). Regulator reputation, enforcement, and environmental compliance. Journal of Environmental Economics and Management, 50(3), 519-540. https://doi.org/10.1016/j.jeem.2005.02.002

Short, J. L., \& Toffel, M. W. (2007). Coerced confessions: Self-policing in the shadow of the regulator. Journal of Law, Economics, and Organization, 24(1), 45-71.

https://doi.org/10.1093/jleo/ewm039

Short, J. L., \& Toffel, M. W. (2010). Making self-regulation more than merely symbolic: The critical role of the legal environment. Administrative Science Quarterly, 55(3), 361-396. https://doi.org/10.2189/asqu.2010.55.3.361

Stafford, S. L. (2011). Outsourcing enforcement: Principles to guide self-policing regimes. Cardozo Law Review, 32, 2293-2323.

Stoughton, M., Herb, J., Sullivan, J., \& Crow, M. (2001). Toward Integrated Approaches to Compliance Assurance. Environmental Law Report, 31, 11266-11283.

Tarlock, D. A. (1992). Environmental Protection: The Potential Misfit Between Equity and 
Efficiency. University of Colorado Law Review, 63, 871-900.

Toffel, M. W., \& Short, J. L. (2011). Coming clean and cleaning up: Does voluntary self-reporting indicate effective self-policing? The Journal of Law and Economics, 54(3), 609-649. https://doi.org/10.1086/658494

Wasserman, C. (1984). Improving the Efficiency and Effectiveness of Compliance Monitoring and Enforcement of Environmental Policies, United States: A National Review. OECD.

Wheeler, D., Hettige, H., Singh, M., \& Pargal, S. (1997). Formal and Informal Regulation of Industrial Pollution: Comparative Evidence from Indonesia and the United States. Policy Research Working Papers. https://doi.org/10.1596/1813-9450-1797

White, C. C. (1996). Regulation of Leaky Underground Fuel Tanks: An Anatomy of Regulatory Failure. UCLA Journal of Environmental Law and Policy, 14, 105-177.

Wiener, J. B. (1999). Global environmental regulation: Instrument choice in legal context. The Yale Law Journal, 108(4), 677. https://doi.org/10.2307/797394

Wooldridge, J. M. (2003). Introductory econometrics: A modern approach (2nd ed.). Australia: South-Western College Pub.

Zinn, M. (2002). Policing Environmental Regulatory Enforcement: Cooperation, Capture and Citizen Suits. Stanford Environmental Law Journal, 21, 81-90.

\section{Glossary}

EPA: Environmental Protection Agency

\section{Appendix}

\section{Appendix 1: Incomplete Response to Survey of Chemical Manufacturing Facilities}

This appendix assesses the incomplete response to our original survey of chemical manufacturing facilities. Given the survey's non-response rate of $73 \%$, the potential for sample selection bias is a valid concern. As the initial assessment of this concern, we compare the original sample of 1,003 potentially eligible facilities to the 267 facilities that actually completed the survey. Based on this comparison, we find no systematic state or regional bias in survey participation. For example, only the Midwest region is slightly over-represented in the response group, and only the Northeast region is slightly under-represented. These differences, however, are small. In addition, across most of the states, the difference between representation in the original sample and representation in the response group averages less than two percent. In contrast, our initial assessment reveals some difference in the participation of major facilities versus minor facilities. In the original sample, 69 percent of facilities are minor facilities and 31 percent are major facilities. In the group of survey respondents, major facilities are slightly over-represented at 39 percent. This difference proves statistically significant.

As a stronger assessment, we test for sample selection bias by assessing whether any relevant 


\section{Ml Macrothink}

Environmental Management and Sustainable Development

ISSN 2164-7682

2020, Vol. 9, No. 2

factors appear to affect a facility's decision to complete our survey once it is contacted. For this assessment, we use a probit model to estimate a functional relationship between the binary decision to complete or not our survey and a set of relevant factors, including major versus minor status, inspections, enforcement actions, and EPA region. This assessment reveals a bias in a single dimension: major facilities were more likely to respond to the survey than were minor facilities. Put differently, the analysis indicates that only the distinction between minor and major facilities proves important for explaining whether or not a contacted facility completed the administered survey. The analysis demonstrates that neither the preceding history of inspections nor the preceding enforcement actions against a particular facility explains whether or not a contacted facility responded to the survey. Moreover, the analysis demonstrates that the decision to respond is not explained by the EPA region in which a particular facility resides. Thus, even if the threat of inspections and enforcement actions varies across EPA regions, this variation does not explain whether or not a contacted facility responds to the survey.

Thus, based on our analysis, it appears that a sample selection bias exists in only a single dimension: the distinction between a "major facility" and a "minor facility". This single distinction proves irrelevant for our final sample of analysis. Therefore, in the end, our study does not correct for any potential sample selection bias. (In particular, we do not employ a Heckman Sample Selection model because no relevant factor proves significant in the first stage of this model, which is the probit estimation noted above.) This lack of correction is consistent with prominently published studies of environmental management practices (Anton et al., 2004; Arimura et al., 2008).

Appendix Table A-1. First-Stage Estimation of Enforcement Fairness

\begin{tabular}{|c|c|c|}
\hline Variable & \multicolumn{2}{|c|}{ Coefficient (p-value) } \\
\hline \multicolumn{3}{|l|}{ Instruments } \\
\hline Only Immunity Audit Policy indicator (lagged) & $-0.050(0.887)$ & \\
\hline Only Privilege Audit Policy indicator (lagged) & $0.136(0.735)$ & \\
\hline Both Immunity and Privilege Audit Policies indicator (lagged) & $0.434(0.049)$ & $* *$ \\
\hline State Inspections Threat (lagged) ${ }^{\mathrm{a}}$ & $-0.136(0.296)$ & \\
\hline Federal Inspections Threat (lagged) $^{\mathrm{a}}$ & $-0.590(0.054)$ & $* *$ \\
\hline \multicolumn{3}{|l|}{ Other Exogenous Factors } \\
\hline Local Community Pressure & $0.025(0.933)$ & \\
\hline Organic Chemical Sub-sector & $0.092(0.670)$ & \\
\hline Inorganic Chemical Sub-sector & $-0.083(0.735)$ & \\
\hline Treatment Technology & $0.273(0.582)$ & \\
\hline Audits & $-0.008(0.260)$ & \\
\hline Firm Ownership Structure & $0.393(0.246)$ & \\
\hline Firm Environmental Employees ${ }^{a}$ & $-0.046(0.277)$ & \\
\hline Informal Enforcement Threat ${ }^{a}$ & $-17.255(0.321)$ & \\
\hline Formal Non-Penalty Enforcement Threat ${ }^{a}$ & N/A & \\
\hline Penalty Enforcement Threat ${ }^{\mathrm{a}}$ & N/A & \\
\hline
\end{tabular}




\begin{tabular}{|l|l|l|}
\hline State Inspections Threat $^{\mathrm{a}}$ & $0.245(0.287)$ & \\
\hline Federal Inspections Threat $^{\mathrm{a}}$ & $-52.052(0.420)$ & \\
\hline Number of Observations & 144 & \\
\hline
\end{tabular}

Robust p-values shown in parentheses.

Asterisks indicate level of statistical significance: * 10\%; ** 5\%; *** $1 \%$.

Regression also includes a constant term and EPA region indicators as regressors.

${ }^{a}$ Regressors enter the estimation in log form.

\section{Copyright Disclaimer}

Copyright for this article is retained by the author(s), with first publication rights granted to the journal.

This is an open-access article distributed under the terms and conditions of the Creative Commons Attribution license (http://creativecommons.org/licenses/by/4.0/). 